\title{
Technology integration through a task-based email project for EFL writing class at tertiary level in Bangladesh
}

\author{
Md. Eftekhar Uddin and Farhiba Ferdous \\ Department of English Language \& Literature \\ International Islamic University Chittagong, Bangladesh
}

\begin{abstract}
This analytical research paper focuses on the affordances of technology integration and taskbased approach in EFL (English as a Foreign Language) writing classroom. The relevant literature review forms the pedagogical underpinning of the task-based email project sketched in this paper. The task with tech-tools like email, power point and Google search engine aims to unfold opportunities for students for the more considerable amount of language production and variety of target language use with the higher level of accuracy both inside and outside the classroom. Besides, the task design ensures effective collaboration necessary in our mixed ability EFL context and empowers students more and makes them active in their learning process. The outlined task also hopes to encourage teachers to design more students-centred activity on sound pedagogy. However, assumed affordances detailed out in this paper need further research to confirm the validity of the study.
\end{abstract}

Keywords Technology integration, Task-based approach, Collaboration, Active learning

Paper type Literature review

\section{Introduction}

Technology that is so much in demand and considered a symbol of social prestige is controlling the whole world today. Technology-assisted language learning has been the innovative norm in target/foreign language teaching as it ensures target language especially writing inside as well as outside the classroom. Apart from motivational impact, communicating with internet in a foreign language, in this case, English, may also ultimately improve the learners' writing skill. The reason is obvious. The learners find the virtual world through electronic media a rich environment for getting input and producing output in a foreign language. Moteram

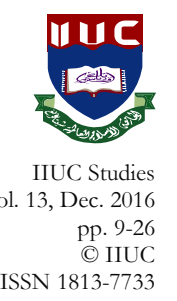




\section{IIUC STUDIES, 13}

(2013) rightly comments in this regard that various technological tools in today's modern world are increasingly playing 'a core part in English Language Teaching (ELT).

On the other hand, the task-based approach in language teaching has been gradually on the rise (See Nunan, 1989, Ellis, 2003). Keeping in mind the growing popularity of technology integration and task-based approach in language learning, we have outlined in this paper a task-based e-mail project. We assume it will create an environment to learn a language, to learn about a language and to learn through a language. Though the amount of writing produced by learners on the internet may be a bit small, learners willing to learn and use target/foreign language can do so only by clicking multitudes of proper links through surfing on the internet. In this way, learners can produce language comparatively with less effort. However, some transitional first steps are needed especially in a technologically disadvantaged context like Bangladesh and the similar ones and using a task-based e-mail project can be a good start in this regard. It is true that in a foreign language classroom all learners may not possess the same level of language and technology proficiency. But it is expected that dedication of learners coupled with the scaffolding of teachers in learning the target language through the sketched task-based email project here, will facilitate learners of varied ability with efficiency in writing skill.

\subsection{Background of the study}

Private universities in Bangladesh in the absence of government funding tend to be generous in admitting students for an apparent reason; more students bring more economic sustainability to the university. As a result, sometimes quantity is achieved at the expense of quality. Still, a good number of meritorious students get admitted into these universities for completing their courses timely which is a surety here but not in government-funded public universities. Our university (International Islamic University Chittagong) is not exclusively different from the trend of a private university. So, class size is large with nearly 50 students in a classroom, and students are of various standards; some belong to intermediate level, some lower intermediate and some beginners.

The department (Department of English Language and Literature) we work in emphasises both English language and literature as its name suggests, though not equally. Language courses are incorporated into the syllabus to equip students with linguistic proficiency so that they could understand literature well. There are four language courses, and two of them focus on improving ability in writing. The courses are 'Advancing 
Writing Skill' and 'Business Writing'. There are three hours in a week and altogether 42 hours in 14 weeks allotted for each course in a semester.

Teachers in our department are assigned with language courses along with literature, so no especial language teacher is here. Both of us taught language courses especially along with other literature courses. From the opinions of our colleagues shared with us, the observations we made on their language courses especially 'writing' coupled with our own experience as teachers, we could say firmly the methodology followed in the writing classes is more or less the same. Some teachers throw a topic with an initial discussion in the form of brainstorming, or sometimes they provide a model followed by some mechanical drills on vital structures used in the model; afterwards, students need to produce a piece of writing on the topic or given model inside the classroom. Besides, students are instructed about the mechanisms and types of writing; topic sentence, adverbial linkers, classifications of paragraphs, essays and the like. So, writing classes are mostly teacher-centered.

Overall, the attitude towards the writing classes for both the teachers and students is not highly motivating. Often, well-knit writing is beyond the grasp of the learners because of linguistic inefficiency, lack of ideas and inability to translate thoughts, if any, in English. All these have been caused by a single reason; here students are not used to writing in English freely and easily outside the classroom. On the other hand, teachers struggle to make the writing classes interesting. The large class setting where all the students can not be reached does not help the course either. It is observed that weaker students who need more help get less attention. But the most worrying thing is despite rigorous correction, which is what we mainly focus on writing classes, students hardly get any benefit from it; they continue to make similar mistakes. So, this makes all teachers, including we two, wonder if there is any use of such correction. Also, flooding submitted pieces of writing with red ink for correction which most students fail to efficiently notice and redeem subsequently makes them de-motivated instead.

For language classes technology is never used in our context but students are familiar with it. There is an internet-facilitated computer-lab in our department consisting of 24 computers used primarily for introductory computer classes. Outside the class time, very few students use it for social networking such as emailing, chatting etc. and also for browsing related materials for literature classes. But students' orientation with computer varies; some are expert, some are familiar with it but do not know how to operate it. There is a self-access listening lab comprising ten tape recorders with related cassettes and books and two multimedia 


\section{IIUC STUDIES, 13}

projectors occasionally used by the teachers only for literature classes. But students hardly utilise them as their syllabus does not necessitate so.

\subsection{Aim of the study}

In this paper, keeping the lack of motivation in EFL writing classes and mixed-ability classroom setting both regarding technology and linguistic proficiency in view, we would like to examine the relevant research on technology integration and task-based approach to building 'a task-based email project'. We hope that it would ensure for students greater amount of language production and variety of target language use with a higher amount of accuracy both inside and outside the classroom. Moreover, this project may prove a practical example to be followed for other teachers with similar context.

\section{Literature Review}

This section examines the pertinent literature on technology integration process and task-based approach in teaching and learning the English language to form the theoretical underpinnings for the 'task-based email project' we are proposing in this paper.

\subsection{Technology integration in language instruction}

Technologies in the form of computers and internet have dramatically revolutionised the way people communicate with others and get access to information worldwide. The world becomes a click away from one's reach. Technology has also brought immense potentials for education and second and foreign language instruction has been the most real beneficiary of it. Lankshear, Snyder, and Green (2000) quite aptly remark that in educational field digital technologies bring forth "authentic forms of social practice and meaning" (p.45). It suggests that computers connected through internet provide opportunities for socialisation and interaction with other language users that facilitate language learning.

According to Topping (1998), to survive in and be a part of this modern techno-based world, students need additional skill called electronic literacy to communicate, gather information, and critically think and evaluate the data presented in this tech-world apart from basic literacy skills. So, the technology in education both supports learning and helps learners achieving electronic literacy needed in the Information age.

Furthermore, technology-integrated instruction with the flexibility of time and space enables teachers to reach learners of varied abilities (Levy, 2000) and to offer guidance, supervision and feedback to learners according to individual needs (Hampel, 2002). Besides, technology affords 
students more control over what they learn and how they learn, and as a result, the role of a teacher becomes a facilitator rather than being a transmitter of knowledge.

On the other hand, researchers note several drawbacks of techmediated teaching (see Schank \& Cleave, 1995). For instance, students may not be able to cope up with a technology-integrated student-centered approach to learning (Schank \& Cleave, 1995). Though technology in the foreign language teaching makes learners active in the learning process and affords students more opportunities and choices, technology solely should not be considered a remedy for all possible hurdles in language learning and teaching, but as an assistive tool for effective facilitation of teaching and learning process, so it needs to be used judiciously to ensure its effectiveness (Davies, 1997, 2005). So, in these studies, awareness has been raised on how teachers can facilitate learners to equip them with skills to take part and function with competence in the online platform.

In brief, the literature reviewed in this section indicates that in our study context, the technology can offer a student-centred approach to learning and facilitate students with electronic literacy necessary in this techno-based world. Also, teachers can reach all students and provide individualised feedback with the flexibility of time and location afforded by technology what might not be possible otherwise. But, for these to happen, teachers need to use technology for social interaction without putting the overemphasis on it as a tool. It should be viewed as an aid, not as a panacea to maximise learning.

\section{2 Technology uses in EFL writing instruction}

Now a days, different kinds of technological tools are in use in writing classrooms in EFL context. A few have been focused on this review.

\section{Classroom Website}

It is now a favourite tool as a repository of teaching and learning resources. Such websites have a motivational value for learners to have the impetus to write for authentic readers (Meyer \& Rose, 2000). The idea of writing for the real audiences is motivation boosters for the learners which pave the way for more writing, hence ensure improved performance in writing.

\section{Blogs}

This tool is an online replica of a personal diary and classroom blogs create a platform for "students to collaboratively write blog entries" (Stout \& Murray, 2008. p.756). According to Seitzinger (2006) Blogs 


\section{IIUC STUDIES, 13}

entries have various affordances for learners such as the development of writing skill, enhancing critical thinking and apprehensibility and promoting active learning avenue.

\section{Wiki}

This tool is also an essential tool for communication which provides learners with an interactive, authentic and collaborative writing environment (Cress \& Kimmerle, 2008; Guzdial et al., 2001; Yukawa, 2006). In Wiki, learners can study, make additional changes for improvement, organise thoughts and also edit the content (Schwartz et al., 2004) and thus mark their traits in language learning. Besides, students can use Wiki for project-based collaborative writings. Hence, they share their knowledge, learn from each others creativity, use socialising skills, and all these are instrumental for language learning (Cress \& Kimmerle, 2008; Guzdial et al., 2001; Yukawa, 2006)

\section{Email}

This widely used medium of communication has been called "the mother of all Internet applications" (Warschauer, Shetzer \& Meloni, 2000, p.3). The world being growingly networked with the internet, email can liberate students from the mechanic drills as "they can be a medium of real communication in the target language, including composing and exchanging messages with other students in the classroom or around the world" (Oxford, 1990, p.79). Besides, email, a familiar tool in our study context can widen the opportunity for learners to have authentic communication even with native speakers and opportune them with "authentic communicative language learning experience" (Gonglewski et al., 2001).

Technology tools reviewed in this section are not all-inclusive instead only a few. Moreover, a variety of devices in writing classrooms are functional, and new ones keep evolving. Against the backdrop of continuously changing tech-tools for classes, researchers consistently make an apt suggestion that these tools need the specific context-sensitive method to fit in. Therefore, integrating technology requires teachers' pedagogical understanding about the affordance of different tools along with the familiarity with them and their suitability in a particular context. Now, we need to focus on how technology-mediated instruction and taskbased approach complement each other. 


\subsection{Task-based Approach}

\subsubsection{Task: Definition}

Different researchers (Richards, Platt \& Weber, 1985; Prabhu, 1987: 2; Nunan, 1989: 10; Willis, 1996: 3; Ellis, 2003: 16) have given different definitions of a task with overlapping similarities. The common characteristics we could draw from these definitions are:

- A task is goal oriented where learners try to arrive at an outcome or achieve an objective.

- The tasks are meaning focused. Focus on grammatical form comes secondary, so it "involves learners in comprehending, manipulating, producing, or interacting in the target language while their attention is principally focused on meaning rather than form". ( Nunan, 2004: 10)

- The task is designed to "result in language use that bears the resemblance, direct and indirect, to the way language is used in the real world". (Ellis, 2003: 16)

\subsubsection{Theoretical Underpinnings of Task-Based Approach}

The task-based approach is underpinned by different insightful thoughts/assumptions about language learning. "Noticing Hypothesis" is one of such assumptions. It is based on the idea that "conscious processing is a necessary condition for one step in the language learning process". (Schmidt, 1990: 131) And the other is "focus on form" approach to language learning proposed by Long (1991). It is unlike traditional structural syllabus approach we practice in our context. Rather, it refers to meaning oriented activities where attention to linguistic features comes reactively or pre-emotively (Lightbown, 1998; Ellis et al., 2001). It is also labelled "interactionalist" as this term is based on the belief that interaction between/among the learners augments learning.

Effective interaction necessitates "negotiation of meaning" and this makes learners to 'focus on form', and help 'noticing' various aspects of forms of a language and all these lead to acquisition. The type of activities among learners that create "negotiation of meaning" have been listed as

(1) confirmation checks, (2) comprehension checks, and (3) clarification requests, as well as (4) repetitions or paraphrases of a previous speaker's or one's utterances (Doughty, 1991: 155) 


\subsubsection{Principles for Designing a Task and its relation to technology integrated language instruction}

Long (1989) suggests the following principles for designing tasks to promote 'negotiation of meaning' instrumental for the acquisition of the target language.

1. Two-way tasks should be preferred to one way task. The former makes the exchange of meaning a must, but the latter does not.

2. Planned tasks encourage more negotiation than unplanned tasks. Learners are made to think beforehand in planned tasks what they are not required to do in the other type of tasks.

3. Closed tasks have a particular solution or target to reach, so they create more negotiation than open task where there is no clear resolution.

4. Convergent tasks generate more negotiation than divergent tasks. In the former, group members must reach a consensus, but in the latter, it is not necessary.

Now the question is whether Second Language Acquisition (SLA) theories derived from classroom research and proposed for classroom can fit in technology integrated language instruction. Chapelle's opinion is relevant here. She opined that only SLA theories only are related to technology-mediated language learning, and are therefore the most effective means of evaluating any tech-integrated task (Chapelle, 1997: 22). In support, she remarks in favour of Long's (1991) interactionalist model of SLA:

...it is useful to view multimedia design(or tech-mediated instruction/task/activity) 'from the perspective of the input it can provide to learners, the output it allows them to produce, the interactions they can engage in, and the L2 tasks it supports (Chapelle, 1998: 26, italics added).

The synergy suggested in our discussion above between SLA, and tech-based language instruction has been the base of the task-based email project we have outlined here.

\section{Task-based Email Project}

Despite meteoric rise in the users of the computer through synchronous and asynchronous tools worldwide for language learning, the idea of techmediated education has been alien in our educational paradigm like other technologically disadvantaged least developed countries in the world. Therefore, an only online based course would be too radical for such contexts to suit, rather, a blended approach combining classroom 
instruction and independent and interactive learning through technological tools such as Email, Google search engine and Power Point presentation would seem more appropriate. That is why we would like to try in our context 'a task-based email project' to create an opportunity for our learners to be independent and interdependent for achieving ease, confidence and efficiency in writing.

\subsection{Our Sample Task-based Email Project}

Aims: At the end of the project students will be able to

- use email, browse through Google search engine and prepare Power Point slides

- use English for communication efficiently and freely

- understand the effectiveness of the group work and collaboration

- be more confident in writing.

Task Topic: Present a comprehensive proposal for a tour in one of the South Asian Association Regional Corporation (SAARC) countries.

\section{Phase 1}

The teacher inside the classroom will announce the task along with the procedure to complete it.

First, the teacher will form eight groups each representing a country. Then, the teacher will take the class to the computer lab to make them familiar with Google search engine.

Afterwards, they will open an email account individually with their teacher and send a text message to each other and to the teacher also. They need to open a new account following the same format so that the teacher can recognise them group wise.

\section{Phase 2}

Each member of a group individually will select and propose first five then three and finally one location representing country using Google search engine.

\section{Phase 3}

Each member then will exchange email sharing their proposals with other members of the group with possible pros and cons about their selection. The group must reach a consensus as they have to propose group-wise. All the members will also talk about through email about the possible outline of their proposal including place, route and budget etc. All 


\section{IIUC STUDIES, 13}

correspondences will be forwarded to the teacher. The teacher might provide scaffolding, if necessary. The group dynamics to work the following assessment policy will be declared.

Marks awarded for:

- The extent to which messages to contribute online debate. Students must include five messages, quote/comments on key points made by others

- Coherence of argument

- Style and presentation

Just before the end of this phase, each student will get an email from the teacher to respond to the following questions and send it back to the teacher.

Checklist:

- How many messages have you sent and how many received?

- Have you come across any new word while exchanging emails? What are those?

- Have you come across any new sentence structures, linking words or phrases while exchanging emails? What are those?

- Have you faced any difficulty in expressing yourself? When? How did you tackle it?

\section{Phase 4}

The teacher will take the students to the computer lab to make them familiar with the process of making Power Point slides.

\section{Phase 5}

Students will work in collaboration in groups to prepare the final presentation and send a copy to the teacher for necessary correction and modification.

\section{Phase 6}

In groups, students will present their proposal in the classroom with a multimedia projector. Other groups along with the teacher will make comments and suggestions on each group presentation. 


\section{Assumed Affordances of the Project}

\subsection{Application of the Task Principles}

Theoretically, now we can say, our task-based email project will generate interaction and negotiation of meaning which aid acquisition of a language as the task has been laid on the principles proposed by Long (1989). The project is a two-way task as the learners work in groups and exchange information among themselves through email about the possible locations for the tour. It is a planned task also. Students need to think beforehand about how to complete the proposal before presenting it in the classroom. Also, it is both a closed and a convergent task. Group members must propose a single location for the tour on which everyone in the group must agree. Moreover, learners in this project need to work in groups to reach an outcome (the proposal of a SAARC tour) and also comprehend, manipulate, produce, or interact in the target language (e.g. through browsing Google for possible locations, exchanging information through email about possible route) concentrating on meaning not on form. But it does not mean the importance of linguistic features in the acquisition process of a language has been overlooked. Instead, it is assumed that learners while facing difficulty in negotiating communication will be able to notice the gap in their inter-language grammar, thus through peer editing can overcome it. And also, a teacher being a facilitator can design the task in such a way that learners notice forms (See 3.2 Phase 3 Checklist) that facilitates acquisition. Above all, the task has the real-life resemblance as looking for and exchanging information and planning a tour are everyday activities in life.

\subsection{Authentic Task facilitating productive environment for learning} According to Newman and Wehlage (1993), the authentic tasks in language classroom are the real world activities that anyone has to be involved in outside world beyond a classroom. The task in our outlined project is not different in this regard. Through such tasks, learners find their relationship between the school and outside world reinforced (Brinton, 1991). They can also see contextualisation of their language learning (Gebhard, 1996), get increased motivation and renewed interest to learn (Melvin \& Stout, 1987). As a result, they gain more confidence in target language use and understand the practical benefits of it in real-world scenarios.

\subsection{Task-Based Project Facilitating Collaboration}

The interaction among learners that our project demands necessitate collaboration both through the computer and around the computer. 
Beatty (2003, p. 102) defines collaboration "as a process in which two or more learners need to work together to achieve a common goal, usually completion of a task or the answering of a question".

\subsubsection{Collaboration Instrumental for Developing Writing Proficiency}

Collaboration through the computer or computer-mediated communication (CMC) through asynchronous means like email has distinct advantages which are important parts of a process approach to writing. Writing through e-mail creates a real purpose and an instant audience and thus generates what Zamel states "a dynamic teaching/learning relationship between writers and their readers" (1983, p.165). Besides, e-mail makes students while collaborating with others like in our project involved in writing activities such as planning, drafting, revising and editing, thus, enhancing the social aspect of writing. Since email increases the opportunities for writing practice beyond the time and space constraints of the traditional classroom setting, students get more time to write at their convenience. As a result, they are likely to process linguistic input with ample time they have in writing and produce more elaborated and complex language. Apart from it, learners using email beyond the classroom walls feel less anxiety which might ensure participation of even shyer and weaker students of the class and result in an increased frequency in writing.

\subsubsection{Collaboration Fostering Negotiation of Meaning in Mixed- Ability Classroom}

In our project, learners also need to collaborate with the computer to prepare the final product with the Power Point. During this collaboration around the computer, students need to continually negotiate meaning, clarify, confirm, repeat, and notice that are necessary conditions for learning to take place.

In our mixed ability large classroom setting, both in terms of language and technology, collaboration may help the weaker students to develop through the assistance of able peers. Vygotsky (1978) calls it 'the zone of proximal development'. It means the range of abilities that a person can perform with assistance from capable peers, but cannot yet perform independently.

\subsubsection{Collaboration for Developing Learning Strategies}

Moreover, a collaborative task enables students to develop a system of learning strategies. They in our project focus and plan for the activities 
(meta-cognitive strategies); they work with peers, interact and understand each other (social strategies); they review structures (memory strategies); they analyse, contrast, and internalise grammatical rules (cognitive strategies); and they predict, guess and express overcoming their 'knowledge gaps' (Jones, 1998, p.122). The developments of these strategies would help students to develop communicative and linguistic competence.

\subsubsection{Collaboration for Active Learning and Motivation}

For success in a collaborative task, it is necessary that each member participates equally and proportionately in a group. Therefore, in our project, there is an assessment policy to ensure active participation of all members in a group (See 3.2-Marks Awarded Section and Checklist in the sample project).

The lack of motivation in writing classes is another issue which, we believe, we can address with our email-based collaborative task. Since group members need to work together to achieve a goal, it will make participants active and hence motivated. The survey conducted by Warschauer (1996) on 167 students in 12 university language classes in three countries can provide further light on this aspect. He has found three factors for students' heightened motivation in email exchanges:

1. The enjoyment of international communication

2. The sense of empowerment in learning process

3. And possible career benefit because of new technological skill

The first factor may not be valid in our context, but the remaining two are.

\subsection{Addressing possible Limitations of the Project}

Email as a medium has the closeness with two modalities: speaking and writing. Few aspects of writing through e-mail are more like speech such as the lack of capitalisation, the use of emoticons, and the use of phonetic spelling etc. So, can this medium facilitate the development of writing?

Baron (1984) comments about the idea of "Computer-Mediated Communication (CMC)" influencing spoken language: "If spoken language is indeed influenced by $\mathrm{CMC}$, we might expect to see an improvement. . . in the degree of logical coherence and grammaticality in our speech, which might begin to approximate more closely that of our written language" (p. 138-39). So, if email, a CMC medium, can develop spoken language, it will have a positive impact on writing as well. Besides, as email is often short in length, learners may feel more inclined to write 


\section{IIUC STUDIES, 13}

in this medium frequently that ultimately make them comfortable and confident in using this mode. And easiness and confidence are the fundamental qualities that help improve writing.

Slaouti (1998), while investigating the role of email in motivating students to write through a project based on email exchange between teachers and student has found that one of her subjects of study developed writing through this email based project beyond her expectation. She said "Perhaps expecting a writing development within the email mode itself was ambitious simply because email is a mode unto itself- a written form of spoken discourse" (p. 12). She found out that her subject was using word processor to redraft so that a more polished copy could be sent, and email was used as a 'mechanism of transport' (p. 12). The same strategy our students might follow if needed. Our opinion in this regard is whether email becomes close to spoken mode or written mode depends on how email project is designed, with whom emails are to be exchanged and for what purpose. In our project, since students are involved in it as a part of academic work and all the correspondences are forwarded to the teacher there must be a sense of formality in their written mode.

\section{Conclusion}

This project based on task-based approach to writing is expected to empower learners, i.e. learners' may have "increased control of the content and process of their learning" (Warschauer et al., 1994). This control over the content and the process of learning which is termed as "learner autonomy" by second language educators is a must for effective language learning (Wenden \& Rubin,1987). Besides, this project is expected to be a small step towards 'normalisation' of technology where the role of technology becomes almost invisible being integrated into the syllabus (Bax, 2003).

Finally, we would like to say that technologies are better suited for learners to interact with each other. But technology itself does not facilitate learning unless it has been tailored to do so. Email may sound a little old-fashioned for promoting collaboration, interaction and learners' autonomy in tech-mediated educational world but in low tech contexts like Bangladesh, it would suit more as learners are more or less familiar with it. 


\section{Reference}

Baron, N. S. (1984). Computer-mediated communication as a force in language change. Visible Language, 18(2), 118-141.

Bax, S. (2003). CALL - past, present and future. System, 31(1), 13-28.

Beatty, K. (2003). Teaching and researching computer-assisted language learning. Harlow: Longman.

Brinton, D. M. (1991). The use of media in language teaching. In M. CelceMurcia (Ed.). Teaching English as a Second or Foreign Language. Boston: Heinle and Heinle Publishers.

Chapelle, C. A. (1997). CALL in the year 2000: still in search of research paradigms? Language Learning \& Technology, 1(1), 19-43.

Chapelle, C. A. (1998). Multimedia CALL: lessons to be learned from research on instructed SLA. Language Learning \& Technology, 2(1), 22-34.

Cress, U., \& Kimmerle, J. (2008). A systemic and cognitive view on collaborative knowledge building with wikis. International Journal of Computer-Supported Collaborative Learning, 3, 105-122.

Davies, G. (1997). Lessons from the past, lessons for the future: 20 years of CALL. In A. K. Korsvold, \& B. Rüschoff (Ed.), New technologies in language learning and teaching, Strasbourg: Council of Europe. Retrieved August 22, 2011, from http://www.camsoftpartners.co.uk/coegdd1.htm

Davies, G. (2005). Computer assisted language learning: where are we now and where are we going? Keynote paper presented at UCALL Conference, University of Ulster at Coleraine. Retrieved August 22, 2011, from http://www.camsoftpartners.co.uk/docs/UCALL_Keynote.htm

Doughty, C. (1991). Second language instruction does make a difference: evidence from an empirical study of SL relativisation. Studies in Second Language Acquisition, 13, 431-469.

Ellis, R., Basturkmen, H., \& Loewen, S. (2001). Pre-emptive focus on form in the ESL classroom. TESOL Quarterly, 35(3), 407-432.

Ellis, R. (2003). Task-based language learning and teaching. Oxford: Oxford University Press.

Gebhard, J. G. (1996). Teaching English as a foreign language: a teacher self-development and methodology guide. Ann Arbor: The University of Michigan Press.

Gonglewski, M., Meloni, C., \& Brant, J. (2001). Using email in foreign language teaching: rationale and suggestions. The Internet TESL Journal, 7(3). Retrieved January 2011, from http://iteslj.org/Techniques/Meloni-Email.html 


\section{IIUC STUDIES, 13}

Guzdial, M., Rick, J., \& Kehoe, C. M. (2001). Beyond adoption to invention: teacher-created collaborative activities in higher education. Journal of the Learning Sciences, 10(3). 265-279.

Hampel, R. (2002). Network-based language teaching today: multimodality, multidimensionality and interaction. In Proceedings of the International Conference on Computers in Education. The Open University: UK.

Jones, S. (1998). Learning Styles and learning strategies: towards student interdependence. Forum for National Language Studies, 34(2), 115-129.

Lankshear, C., Snyder, I., \& Green, B. (2000). Teachers and techno-literacy: managing literacy, technology and learning in schools. Sydney: Allen and Unwin.

Levy, M. (2000). Scope, goals and methods in CALL research: questions of coherence and autonomy. ReCAL, 12(2), 170-195.

Long, M. (1989).Task, group and task-group interactions. University of Hawai'i Working Papers in ESL, 8, 1-26.

Long, M. H. (1991). Focus on form: A design feature in language teaching methodology. In K. de Bot, R. Ginsberg, \& C. Kramsch (Ed.), Foreign language research in cross-cultural perspective (pp. 39-52). Amsterdam: John Benjamins.

Lightbown, P. M. (1998). The importance of timing in focus on form. In Doughty, C., \& Williams, J. (Ed.), Focus on form in classroom second language acquisition (pp. 177-196). Cambridge: Cambridge University Press.

Melvin, B. S., \& Stout, D. S. (1987). Motivating language learners through authentic materials. In W. Rivers (ed.), Interactive Language Teaching (pp. 44-56). New York: Cambridge University Press.

Meyer, A., \& Rose, D. H. (2000). Learning to read in a computer age. Retrieved July 22, 2011, from http://www.cast.org/library/books/ltr/chapter5.html

Moteram, G. (Ed.) (2013). Innovations in learning technologies for English Language Teaching. London: British Council.

Newmann, F. \& Wehlage, G. (1993). Five Standards of Authentic Instruction. Educational Leadership, 55(2), 72-75.

Nunan, D. (1989). Designing tasks for the communicative classroom. Cambridge: Cambridge University Press.

Nunan, D. (1989). Task based language teaching. Cambridge: Cambridge University Press.

Oxford, R. (1990). Language learning strategies. New York: Newbury House.

Prabhu, N. S. (1987). Second language pedagogy. Oxford: Oxford University Press. 
Richards, J., Platt, J., \& Weber. H. (1985). Longman dictionary of applied linguistics. London: Longman.

Schanck, R., \& Cleave, J. (1995). Natural learning, natural teaching: changing human memory. In H. Morowitz, \& J. Singer (Ed.), The mind, the brain and complex, adaptive systems (pp.175-202). Reading, MA: Addison-Wesley.

Schmidt, R. (1990). The role of consciousness in second language learning. Applied Linguistics, 11, 17-45.

Schwartz, L., Clark, S., Cossarin, M., \& Rudloph, J. (2004). Technical evaluation report 6.27. Educational Wikis: Features and selection criteria. The International Review of Research in Open and Distance Learning, 5(1), 1492-3831.

Seitzinger, J. (2006). Be constructive: blogs, podcasts, and wikis as constructivist learning tools. Learning Solutions e-Magazine. Retrieved July 2011 from http://www.elearningguild.com/pdf/2/073106DES.pdf

Slaouti, D. (1998). Motivating learners to write: a role for email. CALL Review: The Journal of the Computer SIG, 9-12.

Stout, M., \& Murray, A. (2008). Blogging to learn English: a report on two blog projects in Japan. In K. Bradford Watts, T. Muller, \& M. Swanson (Ed.), JALT 2007 Conference Proceedings. Tokyo: JALT.

Topping, K. J. (1988). The peer tutoring handbook: promoting co-operative learning. London: Croom Helm.

Warschauer, M. (1996). Motivational aspects of using computers for writing and communication. In M. Warschauer (Ed.), Telecollaboration in foreign language learning (pp. 29-46). Honolulu, HI: University of Hawai'i, Second Language Teaching and Curriculum Center.

Warschauer, M., Turbee, L., \& Roberts, B. (1994). Computer learning network and student empowerment. (SLTCC Research Note \#10). University of Hawaii, Second Language Teaching and Curriculum Center, Honolulu, HI.

Warschauer, M., Shetzer, H., \& Meloni, C. (2000). Internet for English teaching. Alexandria. VA: TESOL Publications.

Wenden, A., Rubin, J. (Eds.). (1987). Learner strategies in language learning. Englewood Cliffs, NJ: Prentice-Hall.

Willis, D. (1996). Accuracy, fluency and conformity. In J. Willis \& D. Willis, Challenge and change in language teaching (Ed.). Oxford: Heinemann Macmillan.

Vygotsky, L. S. (1978). Mind and society: the development of higher psychological process. Cambridge, MA: Harvard University Press. 
26 IIUC STUDIES, 13

Yukawa, J. (2006). Co-reflection in online learning: collaborative critical thinking as narrative. International Journal of Computer-Supported Collaborative Learning, 1, 203-228.

Zamel, V. (1983). The composing process of advanced ESL students: six case studies. TESOL Quarterly, 17(2), 165-187.

\section{Corresponding author}

Md. Eftekhar Uddin can be contacted at: eftuiiuc@yahoo.com 